\title{
Effect of Biofertilizers on the Phenolic Content in a Hybrid Family of Cacao After Leaf Infection with Phytophthora megakarya and Exogenous Application of Salicylic Acid
}

\author{
Simo Claude ${ }^{1,4}$, *, Minyaka Emile ${ }^{3,4}$, Tassong Saah Denis ${ }^{1}$, Njonzo-nzo Stephanie Alvine ${ }^{1}$, \\ Djocgoue Pierre François ${ }^{2,4}$, Taffouo Victor Desire ${ }^{1}$ \\ ${ }^{1}$ Department of Plant Biology, Faculty of Science, University of Douala, Douala, Cameroon \\ ${ }^{2}$ Department of Plant Biology, Faculty of Science, University of Yaoundé 1, Yaoundé, Cameroon \\ ${ }^{3}$ Department of Biochemistry, Faculty of Science, University of Douala, Douala, Cameroon \\ ${ }^{4}$ Laboratory of Plant Physiology, Department of Biological Sciences, Higher Teacher's Training College, University of Yaoundé 1, Yaoundé, \\ Cameroon
}

Email address:

simoclaude@yahoo.fr (S. Claude)

*Corresponding author

\section{To cite this article:}

Simo Claude, Minyaka Emile, Tassong Saah Denis, Njonzo-nzo Stephanie Alvine, Djocgoue Pierre François, Taffouo Victor Desire. Effect of Biofertilizers on the Phenolic Content in a Hybrid Family of Cacao After Leaf Infection with Phytophthora megakarya and Exogenous Application of Salicylic Acid. American Journal of Agriculture and Forestry. Vol. 7, No. 3, 2019, pp. 84-94. doi: 10.11648/j.ajaf.20190703.11

Received: March 31, 2019; Accepted: May 7, 2019; Published: May 29, 2019

\begin{abstract}
In order to protect cacao against Phytophthora megakarya, the most aggressive pathogen of this plant in Cameroon, a study was carried out on hybrid genotypes of the family F79SA of cacao (Theobroma cacao L.) to investigate the effect of inoculation of the biofertilizers Gigaspora margarita and Acaulospora tuberculata on the phenolic compound content in hybrid genotypes after leaf infection with Phytophthora megakarya and treatment of salicylic acid (SA). Thus, the phenolic compound content of hybrid genotypes of the family F79SA of $T$. cacao was evaluated after artificial infection of leaves with $P$. megakarya and treatment of salicylic acid without control and under control of biofertilizers. The artificial infection of $P$. megakarya and exogenous application of salicylic acid resulted in an increase in the accumulation of phenolic compounds (PC) in all genotypes. This increase was more important under the control of Gigaspora margarita and Acaulospora tuberculata and varied from one genotype to another. The PC content analysis map of these genotypes at different treatment conditions under the control of biofertilizers showed a gradual evolution of black coloration, a sign of the increase in phenolic compound content related to concentrations of salicylic acid and infected leaves in all hybrid genotypes thus expressing high tolerance. This map allowed to classify hybrid genotypes according to their level of tolerance. A negative and significant correlation $(\mathrm{P}=$ 0.05) was observed between the development of necrosis and the accumulation of phenolic compounds on one hand and between salicylic acid and the accumulation of phenolic compounds on the other hand. Salicylic acid can therefore be used in the cacao selection program in the absence of the pathogen for the identification of hybrid cacao genotypes as well as in other similar breeding programs.
\end{abstract}

Keywords: Theobroma cacao, Phytophthora megakarya, Gigaspora margarita, Acaulospora tuberculata, Tolerance, Salicylic Acid, Phenolic Compound

\section{Introduction}

Cacao (Theobroma cacao L.) is a major annuity crop in Cameroon and in many producing countries that grows in tropical regions with favourable ecological conditions. Over the last few decades, population growth has led to a considerable demand for cacao as the main ingredient for the chocolate industry. This food product has nutritional properties 
that confer multiple benefits to human health [1-3].

However, cacao-producing countries have diversified soils depending on the cacao-producing regions. Cacao yields are below their potentilas due to long-term cacao culture, depletion of essential soil nutrients, an inadequate soil chemical fertility; which is already a source of environmental pollution and on the other hand, due to the parasitic pressure [4-5]. In most producing countries, there are several pathogens responsible for fungal diseases, including the pathogenic agent Phythopthora megakarya, responsible for the balck pod disease. This pathogen is recognized as the most aggressive in Central and Western Africa. In Cameroon, it is responsible for losses of up to $80 \%$ of the annual yield [6-7].

Studies to improve this culture have not yet produced genotypes completely resistant to Phytophthora megakarya. The use of chemical fungicides, although the most widely used means of control, causes environmental toxicity and pollution problems that affects the quality of cacao sought by chocolate producers and the health of farmers and consumers [8-10]. In addition, microrganisms develop mechanisms for adapting to the regular use of chemical fungicides. Many methods used to fight Phytophthora megakarya directly targets only the microrganism, however while continuing to fight the pathogen, it would also be better to give the host the means to defend himself. As a result, improving the tolerance of cacao genotypes through the use of arbuscular mycorrhizal fungi or the application of a very low concentration of salicylic acid would be an effective, economical, nonpolluting and sustainable means of controlling cacao farming.

Many research results attribute the mycorrhizal symbiosis to a bioprotective effect through a reduction in the pathogenicity of some pest agents and a better tolerance of mycorrhizal plants to stress induced by heavy metals or polycyclic aromatic hydrocarbons [11-12]. This protection of arbuscular mycorrhizal fungi (AMF) against pathogens is certainly linked to a set of processes such as competition for root colonization and nutrient absorption, activation by the fungus of the mechanisms of defense of the plant or even the production of fungal substances disturbing the development of pathogens. The increase in the biosynthesis of phenolic compounds is among the defence mechanisms stimulated by these biofertilizers [13-14].

Several studies have shown that exogenous application of salicylic acid (AS) reduces the inhibitory effects of different biotic and abiotic stresses [15]. Exogenous application of salicylic acid increases the content of phenolic compounds in plants and stimulates the antioxidant complex ascorbic acid GSH [16-17]. Nana et al. demonstrated the accumulation of flavonoid-derived compounds after infection and on the other hand the inhibitory effect of specific phenolic compounds taken from infected pods on P. megakarya [18].

The objective of this work was to improve the tolerance of a hybrid family of Theobroma cacao against the attack of Phytophthora megakarya through the assessment of the phenolic compounds content of the hybrid genotypes of the hybrid family F79SA of $T$. cacao after leaf infection with Phytophthora megakarya and exogenous application of salicylic acid before and after inoculation of biofertilizers Gigaspora margarita and Acaulospora tuberculata. The results obtained will assess the effect of these biofertilizers and salicylic acid against the attack of the pathogen in order to establish a sustainable and effective control technique.

\section{Materials and Methods}

\subsection{Plant Material}

Twenty-four hybrid genotypes from the direct crossing $($ T79/501 $\times$ SNK413) and two parental genotypes SNK413 and T79/501 were used as plant marterial. The parental genotype T79/501, a high Amazonian characterized by low tolerance and parental genotype SNK413, a local Trinitario characterized by tolerance against Phytophthora megakarya were used.

\subsection{Fungal Material}

P. megakarya is a local strain isolated from the Plant Biotechnology Laboratory of IRAD in Ekona from a naturally infected Cocoa pod crop in a cacao plantation in Ekona (South West, Cameroon).

The AMF is a strain derived from a mixture of endomycorrhizal fungi with arbuscules Gigaspora margarita and Acaulospora tuberculata. They were chosen due to their ability to regulate the uptake of nutrients by their host plants (Gigaspora margarita) and to improve tolerance to pathogenic infections (Acaulospora tuberculata) [19-20]. The inoculum consisted of a mixture of spores, mycelium, root fragments and coarse sand. The prepared inoculum was stored in the laboratory at $15-20^{\circ} \mathrm{C}$ after drying. Fifty grams of the mixture were inoculated at a depth of $5 \mathrm{~cm}$ below the surface of the growth medium.

\subsection{Setting up the Nursery}

Plastic pots of $3 \mathrm{~L}$ perforated with small holes of $0.5 \mathrm{~cm}$ in diameter at their bases were filled with humified soil obtained from a mixture of top soil obtained from fallow land at the Faculty of Science of University of Douala and Sawdust fine at a volume proportion of 3:1 (V/V). This mixture was air dried at ambient temperature and sieved using a $2 \mathrm{~mm}$ sieve. The selected beans were washed with tap water added to the fine sand to eliminate the mucilage. On the eve of sowing, the pots were sprinkled and the next day the beans were sown at a density of one bean per pot. Each bean was placed in the middle of each pot by pushing the large end of the seed down to maintain the right pivot and $1 \mathrm{~cm}$ deep. After sowing, the pots were watered regularly at 6:am and at the same time for the first 15 days following sowing, then every 2 days to allow good growth of young shoots.

\subsection{Root Coloration and Mycorrhization Evaluation}

Root staining was carried out as described Philips and Hayman (1970) with the Trypan Blue, which allowed a good coloration of chitin from the walls of the fungus [21]. The frequency and intensity of mycorrhization were calculated 
using the method described by Marx et al. and Trouvelot et al. [22-23].

\subsection{Isolation and Culture of the Strain of Phytopthora Megakarya}

The isolation and culture of P. megakarya was carried out as described by Nyassé et al. and later modified by Coulibaly et al. (2013) [24-25]. A strain of P. megakarya was isolated from a naturally occurring pod of brown rot whose development of necrosis was at the stage of the production of zoospores. This pod was used to infect a healthy pod previously washed with distilled water by putting them side by side in a plastic container soaked in distilled water and incubated at $26^{\circ} \mathrm{C}$ in the dark for two weeks in the laboratory. The newly infected pod washed with tap water underwent a series of $95 \%$ ethanol disinfection, for 30 seconds, in 10\% sodium hypochlorite, for 2 minutes and then in $70 \%$ ethanol for 2 minutes to eliminate microrganisms present on the cortex. After three rinses of the pod with sterile distilled water, the sampling area was selected and the superficial tissues stripped with a sterile scalpel. Five cubic-shaped fragments from this pod, approximately $7 \mathrm{~mm}$ apart, were collected from the subcortical tissues with a sterile cut-off at the necrosis growth front. Each fragment was deposited on a pea-based agar medium contained in petri dishes of diameter $90 \mathrm{~mm}$. Incubation was done in an oven at $26^{\circ} \mathrm{C}$ for 5 days in the dark. The isolates obtained after the formation of the thallus were purified by successive subculturing on the agar medium based on pea contained in petri dishes of diameter $90 \mathrm{~mm}$.

\subsection{Preparation of Inoculum and Counting of Zoospores}

The inoculum was prepared and the count of the zoospores carried out according to the method described by Nyassé et al. (1995) [24]. The strain to be inoculated was pretreated two weeks before on medium pea agar in petri dishes $90 \mathrm{~mm}$ in diameter and incubated in an oven at $26^{\circ} \mathrm{C}$ for 7 days in the dark. The petri dishes were placed alternately for 7 days in the light of an incandescent lamp $(60 \mathrm{~W})$ and in the dark (photoperiod $12 \mathrm{~h} / 12 \mathrm{~h}$ ) at $26^{\circ} \mathrm{C}$ to allow the formation of the sporocysts that are at the origin of the production of the zoospores. During infection, 4 to $5 \mathrm{ml}$ of sterile distilled water was added to each petri dish. These Petri dishes were placed for $30 \mathrm{~min}$ in a refrigerator at $4^{\circ} \mathrm{C}$ to promote the cold shock to release the zoospores contained in the sporocysts. These petri dishes were then maintained at $26^{\circ} \mathrm{C}$ for 2 hours to allow the zoospores to be released into the water contained in each petri dishe, the solution containing the zoospores was then recovered from a beaker. After immobilization of the zoospores by two drops of methylene blue, the zoospores obtained in the beaker were counted using a Malassez hematimetric cell at the concentration of $101 \times 10^{5}$ zoospores $/ \mathrm{ml}$. Counting was performed on optical microscope at objective 40 .

\subsection{Artificial Infection of Leaves in Nursery}

Leaves of about 60 days old not detached from the seedlings were used and divided into two groups: (a) intact leaves (control) and (b) scarified leaves (with fine sand) and then infected with zoospores of P. megakarya (with $6 \mu \mathrm{l}$ suspension of calibrated at $101 \times 10^{5}$ zoospores $\left./ \mathrm{ml}\right)$. The identified leaves were carefully cleaned, infected and covered with hydrophilic cotton and tape. The seedlings were regularly watered for 7 days to promote the conditions necessary for the development of P. megakarya. Seven days after infection, these leaves were harvested and stored for 24 hours at $0^{\circ} \mathrm{C}$ to facilitate grinding. Three repetitions were done for each treatment.

\subsection{Treatment of Leaves with Aalicylic Acid}

Leaves of about 60 days old not detached from the seedlings were used and divided into four groups: (a) intact leaves (control), (b) scarified leaves and inoculated with salicylic acid $(10 \mu \mathrm{l}, 5 \mathrm{mM})$, (c) scarified leaves and inoculated with salicylic acid $(10 \mu \mathrm{l}, 10 \mathrm{mM})$, (d) scarified leaves and inoculated with salicylic acid $(10 \mu \mathrm{l}, 15 \mathrm{mM})$. Three days after inoculation, the leaves were collected and stored at $0^{\circ} \mathrm{C}$ for extraction of phenolic compounds.

\subsection{Extraction and Content Assessment of Phenolic Compounds}

The extraction of phenolic compounds for quantitative analysis was done according to the method described by Simo et al. (2014) [14]. Twenty mg of fresh leaf cut past the necrotic part were crushed in $5 \mathrm{ml}$ of methanol $(80 \%)$ by adding a pinch of sterile fine sand and the resulting maceration was centrifuged at $6000 \mathrm{~g}$ for $20 \mathrm{~min}$. The $\mathrm{S}_{1}$ Supernatant was collected and the culot 1 was recovered in 3 $\mathrm{ml}$ of $(80 \%)$ methanol and centrifuged at $6000 \mathrm{~g}$ for $20 \mathrm{~min}$. The $\mathrm{S}_{2}$ Supernatant was collected and the pellet 2 was eliminated. The Supernatants $S_{1}$ and $S_{2}$ formed the extract for the quantitative analysis of phenolic compounds.

The content of the phenolic compounds was determined according to the method described by Marigo [26] who used the Folin and Ciocalteu reagent (mixture of phosphomolybdic acids). This reagent reduces the phenolic compounds present to a blue molybdenum complex. This complex has its maximum absorption at $725 \mathrm{~nm}$.

The mixture consisting of $2 \mathrm{ml}$ of distilled water, $100 \mu \mathrm{l}$ of crude phenol extract, $250 \mu \mathrm{l}$ of pure Folin and $0.5 \mathrm{ml}$ of $\mathrm{Na}_{2} \mathrm{CO}_{3}$ at $20 \%$ was homogenized and incubated in the incubator at $40^{\circ} \mathrm{C}$ for $20 \mathrm{~min}$. After cooling at ambient temperature, the absorbance of the blue complex formed was read in the Spectrophotometer (BECKAM-UV-1600PC) at $725 \mathrm{~nm}$, against a white in which the extract was replaced by methanol (80\%). The phenolic compound content was determined by reference to the calibration curve established with the galic acid. The phenolic compound contents were expressed in $\mu \mathrm{g} / \mathrm{g}$ of fresh weight of leaves.

\subsection{Statistical Analysis}

The phenolic compound contents were represented as the mean $\pm \mathrm{SD}$. The analysis map of the phenolic compound 
contents of hybrid genotypes was carried out with the Mev software version 4.9.0 for Windows. A correlation and principal component analysis between the daily averages of the necrotic surfaces and the phenolic compound contents of the infected leaves and the different concentrations of salicylic acid were performed by the Spearman method at a 5\% threshold using XLstat software 2014.503.

\section{Results and Discussion}

\subsection{Evaluation of Phenolic Compound Content After Leaf Infection with Phytophthora Megakarya Without Control of Gigaspora Margarita and Acaulospora Tuberculata}

The phenolic compound content was evaluated in the parental genotypes T79/501, SNK413, and the hybrid genotypes F79SA3, F79SA4, F79SA5, F79SA9, and F79SA21 in the absence of Gigaspora margarita and Acaulospora tuberculata. Under healthy conditions, the phenolic compound content was higher in the parental genotype SNK413 $(201 \pm 30 \mu \mathrm{g} / \mathrm{g}$ of FW) compared to the parental genotype T79/501 (149 $\pm 4 \mu \mathrm{g} / \mathrm{g}$ of FW) and hybrid genotypes F79SA4 (306 $\pm 6 \mu \mathrm{g} / \mathrm{g}$ of FW) and F79SA3 (287 $\pm 32 \mu \mathrm{g} / \mathrm{g}$ of FW). Under infectious conditions, parental genotypes and hybrid genotypes were characterized by increases in phenolic compound content. The most significant increases were observed in the parental genotype SNK413 (33.62\%) and in the hybrid genotypes F79SA5 (147.5\%), F79SA21 (51.1\%) and F79SA3 (40.1\%) (Figure 1). The genotypes with the highest phenolic content were the most tolerant. This increase was due to the activation of phenylalanine ammonia lyases (PAL), the enzymes most involved in phenolic metabolism, by the elicitors produced by $P$. megakarya. Our results are in agreement with those of Simo et al. (2014) indicated that the increase in phenolic content under infectious conditions was greater in tolerant individuals [14]. These results are also in agreement with those obtained by Effa et al. (2017) who found that parental or hybrid tolerant genotypes accumulated elevated total phenolic compounds relative to susceptible hybrid genotypes after infection of pods with P. megakarya mycelium [27]. Similar results have already been reported by Boudjeko et al. (2007) and Ondobo et al. (2014) [28-29]. In addition, our result are also in coroboration with those obtained by Minyaka et al. (2017) who indicated that during cacao infection with $P$. megakarya, tolerant hybrid genotypes showed high contents of flavones, whereas sensitive ones showed low contents [30].

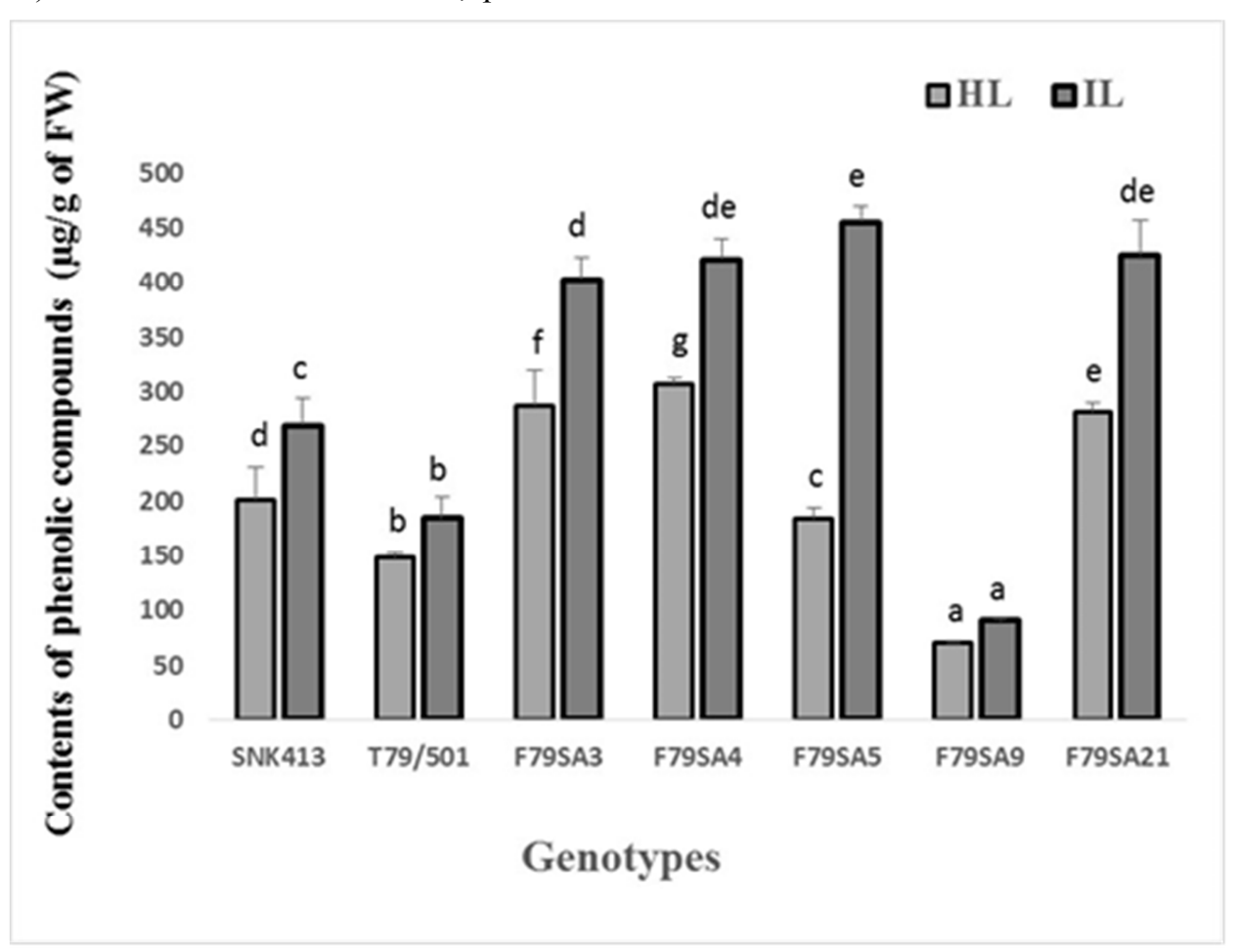

Figure 1. Average of phenolic compound content in the leaves of parental genotypes SNK413 and T79 / 501 and hybrid genotypes of the family F79SA at different treatment conditions without control of Gigaspora margarita and Acaulospora tuberculata. HL: Healthy leaves; IL: Infected leaves.

\subsection{Determination of Phenolic Compound Content After Infection of Phytophthora Megakarya Under the Control of Gigaspora Margarita and Acaulospora Tuberculata}

Phenolic compound content was also evaluated in the hybrid genotypes F79SA1, F79SA5, F79SA9, F79SA10,
F79SA11, F79SA13, F79SA15, F79SA16, and F79SA20 under the control of Gigaspora margarita and Acaulospora tuberculata. Also there is a significant difference in the phenolic compound content within the different hybrid genotypes and between the two treatments (healthy leaves and infected leaves). Under healthy conditions, phenolic 
compound content was higher in F79SA5 hybrid genotypes $(315 \pm 9 \mu \mathrm{g} / \mathrm{g}$ of FW), F79SA11 $(318 \pm 22 \mu \mathrm{g} / \mathrm{g}$ of FW), and F79SA20 $(320 \pm 18 \mu \mathrm{g} / \mathrm{g}$ of FW). Under infectious conditions, hybrid genotypes were also characterized by increases in the content of all hybrid genotypes. The most significant increases were observed in hybrid genotypes F79SA1 (72.04\%) and F79SA9 (64.94\%). Although the phenolic compound content in the F79SA9 and F79SA1 hybrid genotypes was low in the healthy condition under the control of biofertilizers, this content was twice as high as that obtained under the same conditions without control of biofertilizers. Moreover, this increase is more abundant in all hybrid genotypes in healthy condition and in the condition of infection under the control of Gigaspora margarita and Acaulospora tuberculata (Figure 2). The increase in the phenolic content in individuals in healthy conditions and in condition of infection under the control of biofertilizers may be due to the fact that colonization and root infection by the Gigaspora margarita and Acaulospora tuberculata complex mislead the production of elicitors that stimulates the activity of the PAL, the enzyme most involved in phenolic metabolism, transforming phenylalanine into transcynammique acid. These results are consistent with that of Tchameni et al. (2011) that have shown that the biosynthesis of phenolic compounds by cacao plants can be stimulated by several factors, particularly the AMF [31]. Also Nana et al. (2002); Al-Askar and Rashad (2010) and Lu et al. (2015) [34] reported that inoculation with the AMF would promote the biosynthesis of phenols in Cowpea (Vigna unguiculata), Common bean (Phaseolus vulgaris L.), and Yam (Dioscorea spp.) respectively. Moreover, the very large increase in phenolic compounds under infectious conditions may be due to the double activation of PAL by biofertilizers and $P$. megakarya [32-34].

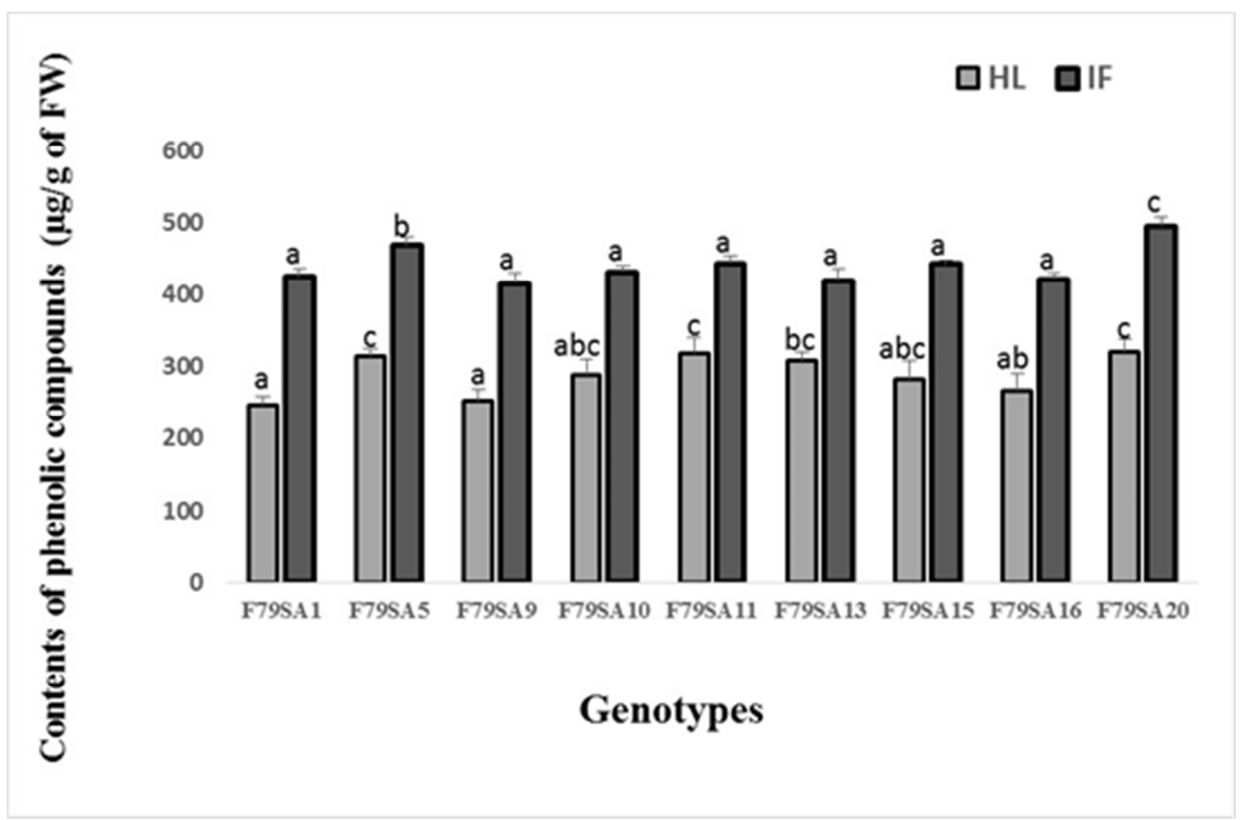

Figure 2. Average of phenolic compound content in the leaves of hybrid genotypes of the family F79SA at different treatment conditions under the control of Gigaspora margarita and Acaulospora tuberculata HL: Healthy leaves; IL: Infected leaves.

\subsection{Assessment of Phenolic Compound Content After Treatment of Leaves with Salicylic Acid Without Control of Gigaspora Margarita and Acaulospora Tuberculata}

The effect of the exogenous contribution of SA in the cacao tree defense system was determined by evaluating the phenolic compound content at different concentrations of SA in parental genotypes T79 / 501, SNK413 and hybrid genotypes F79SA3, F79SA4, F79SA5, F79SA9 and F79SA21 without control of Gigaspora margarita and Acaulospora tuberculata. Significant variations in the phenolic compound content was observed in parental genotypes as well as in hybrid genotypes under healthy condition and at different concentrations except for the hybrid genotypes F79SA3 and F79SA4, which had the same contents at $5 \mathrm{mM}$ and hybrid genotypes F79SA3, F79SA4 and F79SA5 which also had the same contents at concentrations 10 and $15 \mathrm{mM}$. In general, the three concentrations of salicylic acid resulted in a marked increase in the phenol content of all genotypes tested except for the two parental genotypes at $15 \mathrm{mM}$. Under healthy conditions, the accumulation of phenolic compounds was greater in the parental genotype SNK413 $(201 \pm 30 \mu \mathrm{g} / \mathrm{g}$ of FW). This accumulation was even more important in this parent with different concentrations of SA in the parental genotype T79/ 501. In hybrid genotypes, the highest content under healthy conditions was observed in F79SA4 (306 $\pm 6 \mu \mathrm{g} / \mathrm{g}$ of FW) and the lowest in F79SA9 $(71 \pm 0.33 \mu \mathrm{g} / \mathrm{g}$ of FW). Moreover, at $5 \mathrm{mM}$, the highest content was observed in the hybrid genotype F79SA21 (334 $\pm 26.43 \mu \mathrm{g} / \mathrm{g}$ of FW) and the lowest in F79SA9 $(121 \pm 10 \mu \mathrm{g} / \mathrm{g}$ of FW). Similarly, the hybrid genotypes F79SA3, F79SA4 and F79SA5 had the highest levels at 10 and $15 \mathrm{mM}$, although the lowest phenolic compound content was still observed in the hybrid genotype 
F79SA9 $(207 \pm 0.33 \mu \mathrm{g} / \mathrm{g}$ of FW and $125 \pm 16 \mu \mathrm{g} / \mathrm{g}$ of FW, respectively) (Figure 3 ). The treatment of salicylic acid significantly induced the synthesis of phenolic compounds. Our results are in agreement with those of Dihazi et al. (2003) who showed that the application of salicylic acid (SA) in date palm seedlings improved their resistance against Fusarium oxysporum, the causative agent of Bayoud's disease, by stimulating the synthesis of phenolic compounds [35]. This increase in phenol content was due to the activation of phenylalanine ammonia-lyase (PAL) demonstrated as a result of root treatment with salicylic acid. Stimulation of PAL activity has often been correlated with salicylic acid content and plant resistance to pathogens [3638]. Mandal et al. (2009) showed that salicylic acid induces resistance to pathogens by also increasing the activities of phenylalanine ammonia-lyase [39]. These results are also consistent with those of Housti et al. (2002) who showed increased accumulation of lignins and their precursors in the walls of $T$. alata cells treated with salicylic acid [40]. In addition, the work of Tania et al. (2014) indicated that PAL activity in tomato leaves is also triggered by application of salicylic acid [41].

From the three concentrations of salicylic acid used, 10 $\mathrm{mM}$ was the one that induced mostly the synthesis of phenolic compound contents in all genotypes tested without control of Gigaspora margarita and Acaulospora tuberculata. These results are in contradiction with those of Tania et al. (2014) who found that treatments of tomato seedlings with lower salicylic acid concentrations $(1.5 \mathrm{mM})$ would result to an increase in the phenol content 7 days after infection [41]. Our results are also contrary to those obtained by Don et al. (2010) who showed that in Salvia miltiorrhiza cell culture, the elicitation effect depended on the dose of salicylic acid and the time elapsed with low salicylic acid concentrations [42].

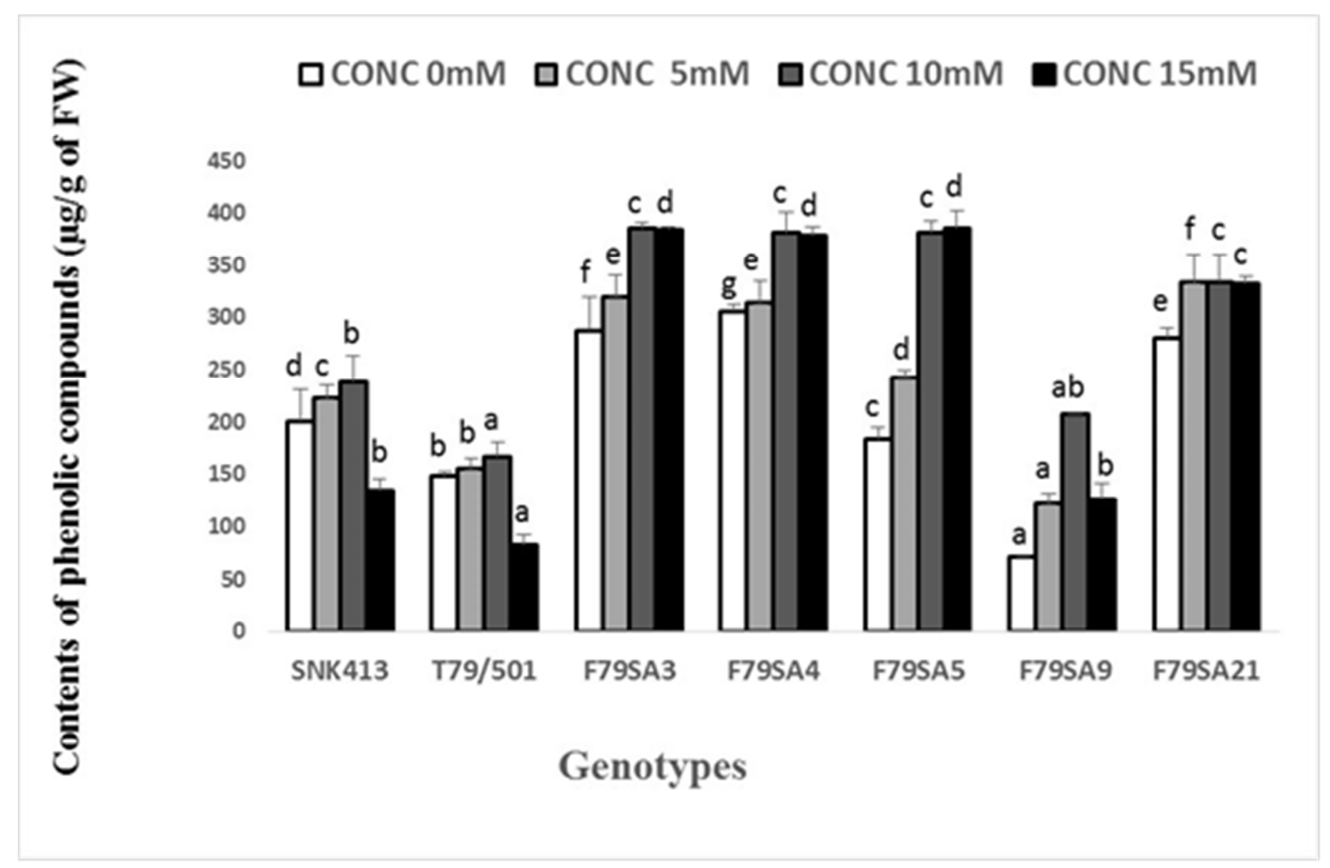

Figure 3. Average of phenolic compound content in the leaves of parental genotypes SNK413 and T79 / 501 and hybrid genotypes of the family F79SA at different treatment conditions without control of Gigaspora margarita and Acaulospora tuberculata.

\subsection{Assessment of Phenolic Compound Content After Treatment of Leaves with Salicylic Acid Under the Control of Gigaspora Margarita and Acaulospora Tuberculata}

Under control of Gigaspora margarita and Acaulospora tuberculata a significant variation in phenolic compound content was observed in all hybrid genotypes under healthy conditions and at 10 and $15 \mathrm{mM}$ concentrations. Under healthy conditions the highest content was observed in hybrid genotypes F79SA20 $(320 \pm 18 \mu \mathrm{g} / \mathrm{g}$ of FW), F79SA11 $(318 \pm 22 \mu \mathrm{g} / \mathrm{g}$ of FW) and F79SA5 (315 \pm 9 $\mu \mathrm{g} / \mathrm{g}$ of FW) and lowest in F79SA1 hybrid genotypes $(247 \pm 12 \mu \mathrm{g} / \mathrm{g}$ of FW) and F79SA9 $(252 \pm 16 \mu \mathrm{g} / \mathrm{g}$ of $\mathrm{FW})$. At $5 \mathrm{mM}$, no significant difference between the different hybrid genotypes were observed. In addition, the hybrid genotypes F79SA1 and F79SA20 had the highest levels at the 10 and $15 \mathrm{mM}$ concentrations. In all these genotypes, the phenolic compound content increased significantly with all salicylic acid treatments compared with the control $(0 \mathrm{mM})$, but this increase was more abundant at $10 \mathrm{mM}$ and $15 \mathrm{mM}$ concentrations respectively, with highest percentages being $93.30 \%$ and $79.76 \%$ in the same hybrid genotype F79SA1 (Figure 4). In general, biofertilizers significantly increased the phenolic compound content in all hybrid genotypes showing an increase in tolerance. This sharp increase would be due to a double activation of the PAL by Gigaspora margarita and Acaulospora tuberculata and salicylic acid. 


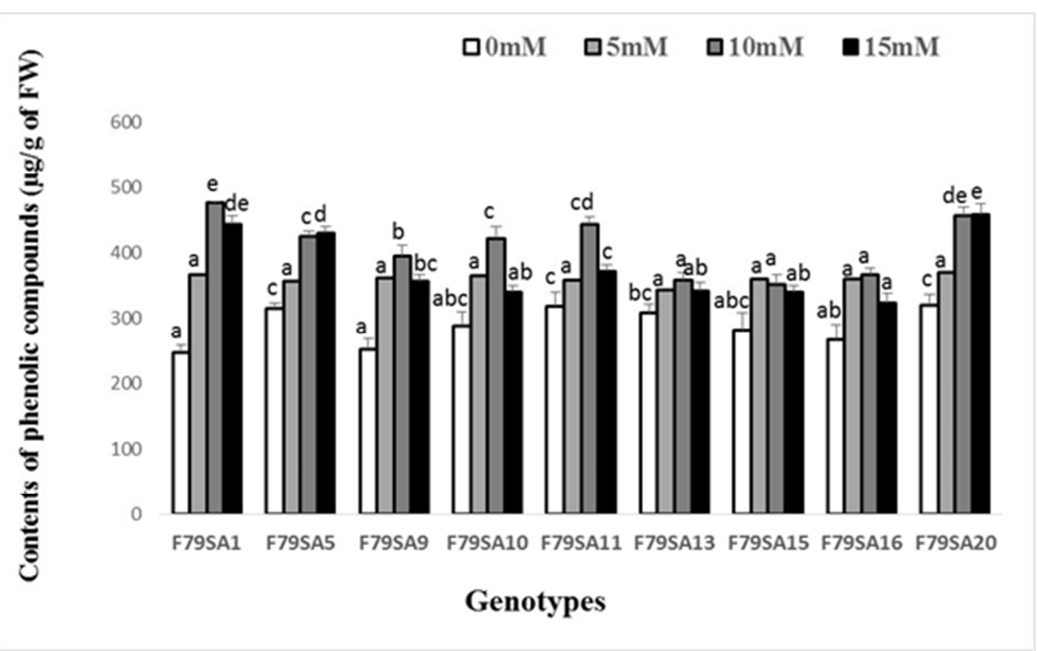

Figure 4. Average of phenolic compound content in the leaves of the hybrid genotypes of the family F79SA at different concentrations of salicylic acid under the control of Gigaspora margarita and Acaulospora tuberculata.

\subsection{Analysis Map of Phenolic Compound Content Without and Under Control of Gigaspora Margarita and Acaulospora Tuberculata}

The analysis map of phenolic compound content of cacao leaves at different treatment conditions of parental genotypes and hybrid genotypes of offspring F79SA without control of Gigaspora margarita and Acaulospora tuberculata showed a progressive evolution of the black coloring sign of the increase in the phenolic compound content of the $0-15 \mathrm{mM}$ concentrations and infected leaves in the hybrid genotypes F79SA5, F79SA3, F79SA4 and F79SA21. However, a decrease of black staining in favor of yellow staining was observed in the hybrid genotype F79SA9 and in the parental genotypes T79 / 501 and SNK413 thus marking a decrease in the content of phenolic compounds and therefore a decrease in stimulation of the plant defense system by salicylic acid at $15 \mathrm{mM}$ concentration. Under infectious conditions, an intense black coloration was observed compared to that observed after salicylic acid treatments in most hybrid genotypes (Figure 5).

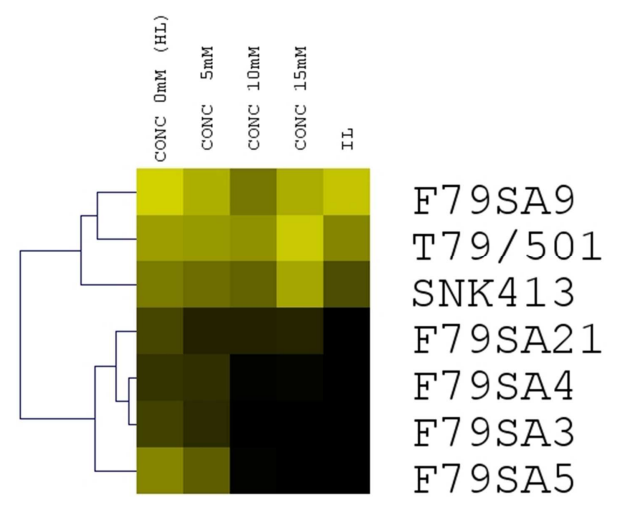

Figure 5. Analysis map of phenolic compound content of cacao leaves at different treatment conditions of parental genotypes and hybrid genotypes of offspring F79SA without control of Gigaspora margarita and Acaulospora tuberculata.
Under control of Gigaspora margarita and Acaulospora tuberculata, the analysis map of phenolic compound content of cacao leaves at different treatment conditions of the hybrid genotypes of the offspring F79SA also showed a progressive evolution of the black coloration, sign of the increase of the phenolic compound contents of the $0-15 \mathrm{mM}$ concentrations and infected leaves in all hybrid genotypes (Figure 6). However, black staining is more intense in the hybrid genotypes tested under the control of Gigaspora margarita and Acaulospora tuberculata, which were characterized by high tolerance in these hybrid genotypes (Figure 6).

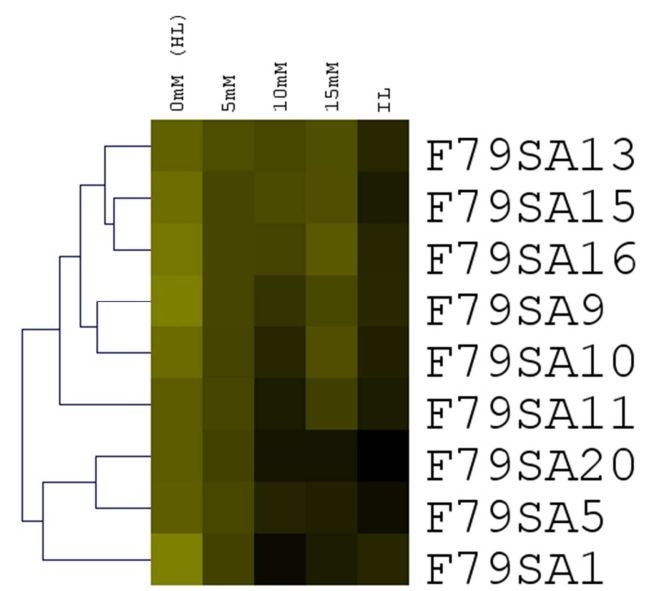

Figure 6. Analysis map of phenolic compound content of cacao leaves at different treatment conditions of hybrid genotypes of offspring F79SA under the control of Gigaspora margarita and Acaulospora tuberculata.

The results of the two map analysis of phenolic compound contents of cacao leaves at different treatment conditions without control and under control of Gigaspora margarita and Acaulospora tuberculata had once again shown that this content was lower in the control leaves compared to the treated leaves and obviously higher in the condition of infection by Phytophthora megakarya. These results also showed that the phenolic compound content was higher in all genotypes under control compared to that 
obtained without control of Gigaspora margarita and Acaulospora tuberculata. These results showed that regardless of the salicylic acid concentrations used to stimulate the plant's defense system, the attack of the plant by the pathogen Phytophthora megakarya was the only most effective method for stimulating this defense system in the plant. However, these results also showed that in the absence of the pathogen, salicylic acid could be used in the breeding program.

\subsection{Frequency and Intensity of Mycorrhization of Gigaspora Margarita and Acaulospora Tuberculata}

The frequency of mycorrhization was not significantly different though there was a frequency mycorrhization of greater than $86 \%$ obtained in all the individuals studied. However, no significant difference was observed in these individuals studied. The intensity of mycorrhization with a rate lower than $50 \%$ was not aslo significant different in all the individuals studied.

\subsection{Study of the Correlations Between the Studied Parameters}

The correlation between necrosis variables, phenolic compounds of infected leaves (PC IL), phenolic compounds of salicylic acid (PC SA) $5 \mathrm{mM}$, phenolic compounds of salicylic acid (PC SA) $10 \mathrm{mM}$ and phenolic compounds of the salicylic acid (PC SA) $15 \mathrm{mM}$ without control of Gigaspora margarita and Acaulospora tuberculata showed that the necrosis was negatively and significantly correlated with PC IL, PC SA 5mM, PC SA $10 \mathrm{mM}$ and PC SA $15 \mathrm{mM}$ at the alpha threshold $\mathrm{P}=0.05$ $\left(r^{2}=-0.823,-0.680,-0.832,-0.839\right.$ respectively, $\left.\mathrm{P}=0.05\right)$. These results are similar to the work done by Effa et al. (2017) who showed that there was a negative and significant correlation between necrosis and the three metabolites (polyphenols, proline and amino acids) in cacao [27]. These results are also consistent with those obtained by Tchameni et al. (2017) who showed that there was a negative correlation $\left(\mathrm{P}=0.002, \mathrm{r}^{2}=-0.86\right)$ between the total soluble phenolics content and the disease index in the study of Trichoderma asperellum against Phytophthora megakarya in cacao [43]. On the other hand, there was a significant $(\mathrm{P}=0.05)$ positive correlation between the content of phenolic compounds in the infected leaves (PC IL) and that of the different concentrations of salicylic acid (Table 1).

Table 1. Correlation matrix showing the relationship between daily averages of necrotic surfaces and phenolic compound contents of infected leaves and different concentrations of salicylic acid without the control of Gigaspora Margarita and Acaulospora tuberculata.

\begin{tabular}{llllll}
\hline Variables & Necrosis & PC IL & PC SA 5mM & PC SA 10mM & PC SA 15mM \\
\hline Necrosis & 1 & & & & \\
PC IL & $-0,823$ & 1 & & & \\
PC SA 5mM & $-0,680$ & 0,783 & 1 & 1 & 1 \\
PC SA 10mM & $-0,832$ & 0,704 & 0,675 & 0,938 & 1 \\
PC SA 15mM & $-0,839$ & 0,719 & 0,707 & & \\
\hline
\end{tabular}

Bold values are significant at threshold Alpha $\mathrm{P}=0.05$.

The principal component analysis performed between these non-control variables of Gigaspora margarita and Acaulospora tuberculata was also used to coroborate these correlations. Axes 1 and 2 represent $90.97 \%$ of the total variability. This is indicated on the axis F1 and F2 with 81.69 and $9.28 \%$ of the total variance respectively. Thus, the necrosis variables were negatively and significantly $(\mathrm{P}=0.05)$ associated with the PC SA $5 \mathrm{mM}$, PC IL, PC SA $15 \mathrm{mM}$ and PC SA $10 \mathrm{mM}$ variables on the F1 axis. The F2 axis had no variable that was significantly associated with it (Figure 7).

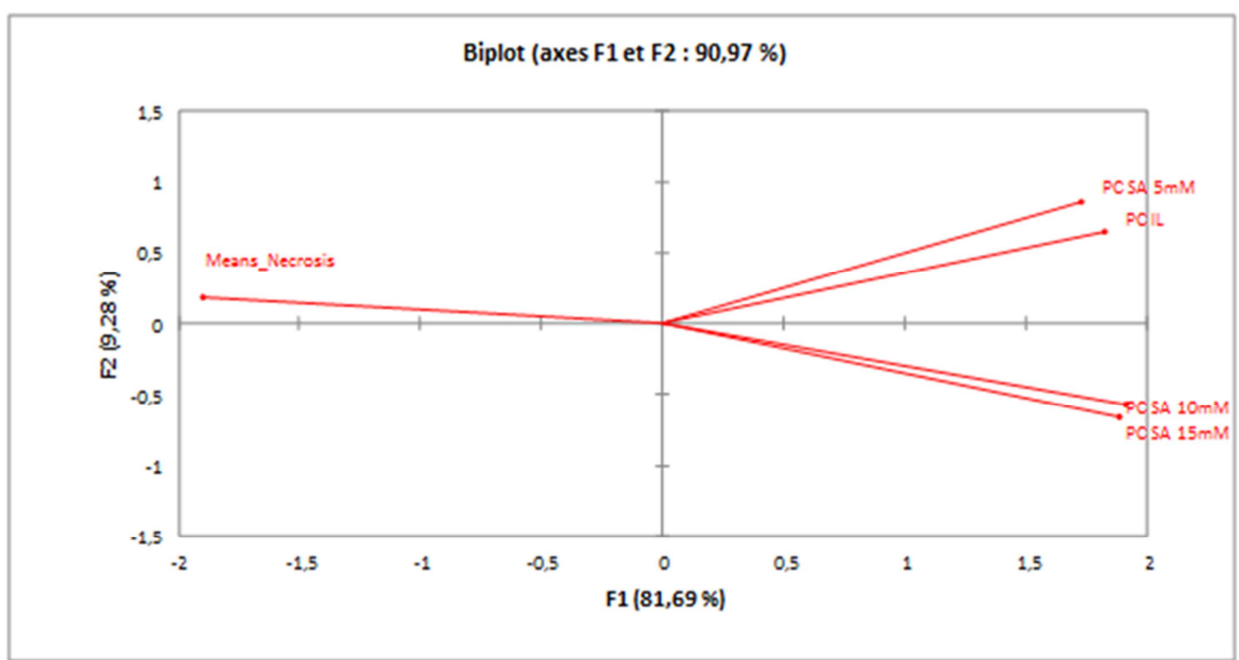

Figure 7. Principal component analysis showing the relationship between the daily averages of necrotic surfaces, phenolic compound contents of infected leaves and different concentrations of salicylic acid without the ontrol of Gigaspora margarita and Acaulospora tuberculata. 
Moreover, the correlation between the necrosis, PC IL, PC SA $5 \mathrm{mM}$, PC SA $10 \mathrm{mM}$ and PC SA $15 \mathrm{mM}$ under the control of Gigaspora margarita and Acaulospora tuberculata showed that the necrosis was negatively and significantly correlated with PC IL, PC SA 10mM, PC SA $15 \mathrm{mM}$ and not significantly correlated with $5 \mathrm{mM} \mathrm{PC}$ SA at the alpha threshold $\mathrm{P}=0.05\left(\mathrm{r}^{2}=-0.59,-0.556,-0.657, \mathrm{P}=0.05\right)$. The correlation was positive and non-significant between PC IL, PC SA 5mM and PC SA $10 \mathrm{mM}$ but positive and significant between PC IL and PC SA $15 \mathrm{mM}$. Between the phenolic compound content of the three SA treatments, the correlation was positive but was significant $(\mathrm{P}=0.05)$ only between $10 \mathrm{mM}$ PC SA and $15 \mathrm{mM}$ PC SA (Table 2).

Table 2. Correlation matrix showing the relationship between the daily averages of necrotic surfaces and phenolic compound contents of infected leaves and different concentrations of salicylic acid under the control of Gigaspora margarita and Acaulospora tuberculata.

\begin{tabular}{lllll}
\hline Variables & Necrosis & PC IL & PC SA 5mM & PC SA 10mM \\
\hline Necrosis & $\mathbf{1}$ & & & \\
\hline PC IL & $-0,597$ & 1 & & \\
PC SA 5mM & $-0,175$ & 0,167 & 1 & 1 \\
PC SA 10mM & $-0,556$ & 0,353 & 0,352 & 0,775 \\
PC SA 15mM & $-0,657$ & 0,562 & 0,232 & 1 \\
\hline
\end{tabular}

Bold values are significant at threshold Alpha $\mathrm{P}=0.05$.

The principal component analysis performed between these variables under the control of Gigaspora margarita and Acaulospora tuberculata also allowed to visualize these correlations. Axes 1 and 2 represent $76.45 \%$ of the total variability. This is indicated on the the axis F1 and F2 with
57.55 and $18.89 \%$ of the total variance respectively. Thus, the necrosis variables were negatively and significantly associated with the $10 \mathrm{mM}$ PC SA, the $15 \mathrm{mM} \mathrm{PC} \mathrm{SA} \mathrm{and}$ the PC IL on the F1 axis, while the $5 \mathrm{mM}$ PC SA was individualized on the F2 axis (Figure 8).

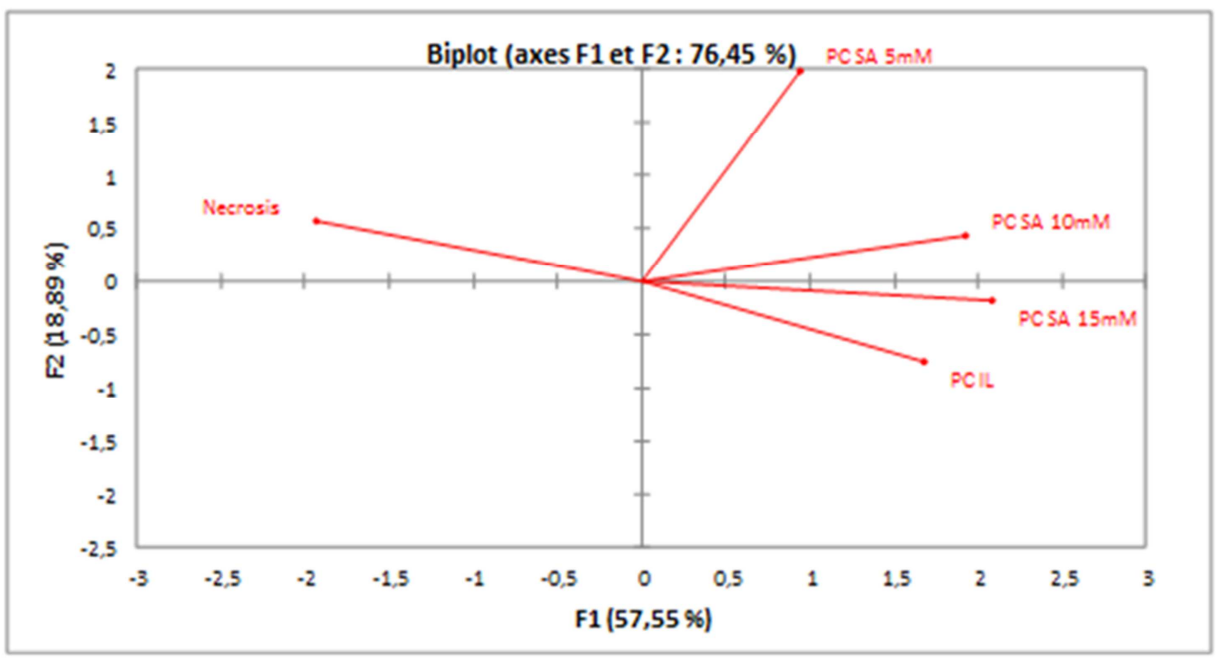

Figure 8. Principal component analysis showing the relationship between the daily averages of necrotic surfaces, phenolic compound contents of infected leaves and different concentrations of Salicylic acid under control of Gigaspora margarita and Acaulospora tuberculata.

\section{Conclusion}

In this study, it appears that in the absence of the biofertilizers Gigaspora margarita and Acaulospora tuberculata, the phenolic content was higher in the tolerant parent (SNK413) and the hybrid genotypes F79SA4, F79SA21, F79SA3 and F79SA5 than in the susceptible parent $(\mathrm{T} 79 / 501)$ and the sensitive hybrid genotype F79SA9 under healthy and infectious conditions. Under the control of biofertilizers, an improvement of the defense system was observed in all the hybrid genotypes studied. Without control of the biofertilizers, the various treatments of salicylic acid resulted in a significant increase in the content of phenolic compounds and the $10 \mathrm{mM}$ concentration was the one having the most effect. The same results were obtained under the control of biofertilizers but with a strong amplification in all the genotypes and all the treatments. Treatment of salicylic acid increased the PC content of the cacao genotypes, but this increase is amplified in the presence of Gigaspora margarita and Acaulospora tuberculata. In addition, salicylic acid can be used in the cacao selection program in the absence of the pathogen for the identification of hybrid genotypes of cacao as well as in other similar breeding programs.

\section{Acknowledgements}

SIMO Claude and the co-authors thank the Laboratory of the Institute for Genetics of the University of Cologne for some analyzes that have been done and the Plant Biotechnology 
laboratory of the Institute of Agricultural Research for Development (IRAD) of Ekona for the training of some coauthors in the framework of this project.

\section{References}

[1] Fidelis C, Rajashekhar Rao B K. Enriched Cocoa pod composts and their effects on hybrid Cocoa seedlings. International Journal of Recycling of Organic Waste in Agriculture. 2017, 6 (2): 99-106.

[2] Shahin S A, Jonathan S, Lary D J, et al. Phytophthora megakarya and Phytophthora palmivora, Closely Related Causal Agents of Cacao Black Pod Rot, underwent increases in genome sizes and gene numbers by different mechanisms. Genome Biology and Evolution. 2017a, 9 (3): 536-557.

[3] Shahin S A, Jonathan S, Lary D J, et al. Phytophthora megakarya and P. palmivora, causal agents of black pod rot, induce similar plant defense responses late during infection of susceptible cacao pods. Frontiers in Plant Science. 2017b, 8: $1-18$.

[4] Gidoin C, Babin R, Bagny Beilhe L, et al. Tree Spatial Structure, Host Composition and Resource Availability Influence Mirid Density or Black Pod Prevalence in Cacao Agroforests in Cameroon. PLoS ONE. 2014, 9: e109405. doi: 10.1371/journal.pone.0109405.

[5] Doungous O, Minyaka E, Longue E, et al. Potentials of Cocoa pod husk-based compost on Phytophthora pod rot disease suppression, soil fertility, and Theobroma cacao L. growth. Environmental Science and Pollution Research. 2018, 25: $25327-25335$.

[6] Ndoumbe-Nkeng M, Efombagn M I B, Bidzanga N L, et al. Spatio-temporal dynamics on a plot scale of Cocoa black pod rot caused by Phytophthora megakarya in Cameroon. European Journal of Plant Pathology. 2017, 147: 579-590.

[7] Simo C, Djocgoue P F, Minyaka E, et al. Guaiacol Peroxidase heritability in tolerance of Cocoa (Theobroma cacao L.) to Phytophthora megakarya, agent of Cocoa black pod disease. International Journal of Agricultural Policy and Research. 2018, 6 (2): 7-20.

[8] Deberdt P, Mfegue C V, Tondje P R, et al. Impact of environmental factors, chemical fungicide and biological control on cacao pod production dynamics and black pod disease (Phytophthora megakarya) in Cameroon. Biological Control. 2008, 44 (2): 149-159.

[9] Opoku I, Akrofi A, Appiah A. Assessment of sanitation and fungicide application directed at Cocoa tree trunks for the control of Phytophthora black pod infections in pods growing in the canopy. European Journal of Plant Pathology. 2007, 117: $167-175$.

[10] Nyadanu D, Akromah R, Adomako B, et al. Host plant resistance to Phytophthora pod rot in Cocoa (Theobroma cacao L.): The role of epicuticular wax on pod and leaf surfaces. International Journal of botany. 2012, 8 (1): 13-21.

[11] Akthar M S, Siddiqui Z A. Arbuscular Mycorrhizal Fungi as Potential Bioprotectants against Plant Pathogens. Sustainable Agriculture and Forestry. 2008, 61-97.

[12] Joner E J, Leyval C. Rhizosphere gradients of polycyclic aramatic hydrocarbon (PAH) dissispation in two industrial soils and the impact of arbuscular mycorrhiza. Environmental Science and Technology. 2003, 37 (11): 2371-2375.

[13] Fokom R, Nana W L, Tchameni S, et al. Arbuscular Mycorrhizal Fungi (AMF) colonisation and rhizobia nodulation of cowpeaas affected by flavonoid application. Research Journal of Agriculture and Biological Sciences. 2010, 6 (6): 1015-1021.

[14] Simo C, Djocgoue P F, Mbouobda H D, et al. Assessing relationship between phenolic compounds and resistance to Phytophthora megakarya using two Cocoa (Theobroma cacao L.) families. African Journal of Biotechnology. 2014, 13: 2956-2965.

[15] Hayat Q, Hayat S, Irfan M, et al. Effect of exogenous Salicylic sacid under changing environment. Environmental and Experimental Botany. 2010, 68: 14-25.

[16] Bechtold U, Karpinski S, Mullineaux P. The influence of the light environment and photosynthesis on oxidative signalling responses in plant-biotrophic pathogen interactions. Plant Cell Environment. 2005, 28: 1046-1055.

[17] Chao Y Y, Chen C Y, Huang W D, et al. Salicylic acidmediated hydrogen peroxide accumulation and protection against Cd toxicity in rice leaves. Plant and Soil. 2010, 329: 327-337.

[18] Nana W L, Tchameni N S, Fokom R, et al. Flavonoïd compounds synthesis by Cocoa fruits (Theobroma cacao L.) in response to Phytophthora megakarya infection. Research Journal of Agriculture and Biological Sciences. 2011, 7: 335342 .

[19] Ngonkeu M E L. 2009. Tolérance de certaines variétés de maïs aux sols à toxicité aluminique et manganique du Cameroun et diversités moléculaire et fonctionnelle des mycorhizes à arbuscules. Thèse, Université de Yaoundé I, Cameroun, 224 p.

[20] Tchameni N S, Nwaga D, Nana W L, et al. Growth enhancement, amino acid synthesis and reduction in susceptibility towards Phytophthora megakarya by arbuscular mycorrhizal fungi inoculation Cocoa plants. Journal of Phytopathology. 2012. 160: 220-228.

[21] Phillips J M, Hayman D S. Improved Procedures for Clearing Roots and Staining Parasitic Vesicular- Arbuscular Mycorrhizal Fungi for Rapid Assessment of Infection. Transactions of the British Mycological Society. 1970, 55: 158-161.

[22] Marx H D, Bryan W C, Cordell C E. Survival and growth of Pine seedlings with Pisolithus ectomy-corrhizae after two years on reforestation sites in North Carolina and Florida. Forest science. 1977, 3: 363-373.

[23] Trouvelot A, Kough J, Gianinazzi-Pearson V. Evaluation of VA infection levels in root systems. Research for estimation methods having a functional significance. In: V. GianinazziPearson and S. Gianinazzi (eds.), Physiological and Genetical Aspects of Mycorrhizae. INRA Press, Paris, France. 1986, 217-221.

[24] Nyassé S, Cilas C, Herail C, et al. Leaf inoculations as an early screening test for Cocoa (Theobroma cacao L.) resistance to Phytophthora black pod disease. Crop Protection. 1995, 14: 657-663. 
[25] Coulibaly K, Kebe I B, Koffi N K, et al. Caractérisation des isolats de Phytophthora sp. du verger cacaoyers de Cote d'Ivoire. Journal of Applied. Biosciences. 2013, 70: 55675579 .

[26] Marigo G. Sur une méthode de fractionnement et d'estimation des composés phénoliques chez les végétaux. Analysis. 1973, 2: $106-110$

[27] Effa O P, Manga N J, Ondobo L M, et al. Virulence Test of Some Phytophthora Megakarya Isolates on Cocoa (Theobroma Cacao L.) Hybrid Pods. IOSR Journal of Biotechnology and Biochemistry. 2017, 3 (1): 73-81.

[28] Boudjeko T, Djocgoue P F, Nankeu D J, et al. Luteolin derivatives and heritability of resistance in the Theobroma cacao L. (Cacao)/Phytophthora megakarya Bras and Griff interaction. Australisian Plant Pathology. 2007, 36: 56-61.

[29] Ondobo M L, Effa O P, Djocgoue P F, et al. Phenolic content and heritability of resistance in four hybrid populations of Theobroma cacao L. after leaves inoculation with Phytophthora megakarya Bras. and Grif. International Journal of Biological and Chemical Sciences. 2014, 8 (1):1730 .

[30] Minyaka E, Simo C, Kusznierewicz B, et al. Flavones in Cocoa Defence against Phytophthora megakarya. Journal of Botanical Sciences. 2017, 6 (3): 50-63.

[31] Tchameni S N, Ngonkeu M E L, Begoude B A D, et al. Effect of Trichoderma asperellum and arbuscular mycorrhizal fungi on cacao growth and resistance against black pod disease. Crop Protection. 2011, 30: 1321-1327.

[32] Nana W L, Nwaga D, Fokom R, et al. Variation des composés phénoliques chez Vigna unguiculata (L.) Walp. (Légumineuse) et influence des rhizobia et des mycorhizes sur leur biosynthèse. African Journal of Science and Technology. 2002, 3 (2): 127-135.

[33] AL-Askar A A, Rashad Y M. Arbuscular mycorrhizal fungi: a biocontrol agent against common bean Fusarium root rot disease. Plant Pathology Journal. 2010, 9: 31-38.

[34] Lu F C, Lee C Y, Wang C L. The influence of arbuscular mycorrhizal fungi inoculation on yam (Dioscorea spp.) tuber weights and secondary metabolite content. Peer Journal. 2015, DOI: 10.7717/peerj.1266.
[35] Dihazi A, J'aity F, Zouine J, et al. Effect of Salicylic acid on phenolic compounds related to date palm resistance to Fusarium oxysporum f. sp. albedinis. Phytopathologia Mediterranea. 2003, 42 (1): 9-16.

[36] Patel M, Kothari I L, Mohan J S. Plant defense induced in vitro propagated banana (Musa paradisiaca) plantlets by Fusarium derived elicitors. Indian Journal of Experimental Biology. 2004, 42: 728-731.

[37] Arfaoui A, El Hadrami A, Mabrouk Y, et al. Treatment of chickpea with Rhizobium isolates enhances the expression of phenylpropanoid defense-related genes in response to infection by Fusarium oxysporum f. sp. Ciceris. Plant Physiology and Biochemistry. 2007, 45: 470-479.

[38] Wang X, El Hadrami A, Adam L R, et al. Differential activation and suppression of potato defence responses by Phytophthora infestans isolates representing US-1 and US-8 genotypes. Plant Patholology. 2008, 57 (6): 1026-1037.

[39] Mandal S, Mallick N, Mitra A. Salicylic acid-induced resistance to Fusarium oxysporum f. sp. lycopersici in tomato. Plant Physiology and Biochemistry. 2009, 47: 642-649.

[40] Housti F, Andary C, Gargadenne A, et al. Effects of wounding and Salicylic acid on hydroxycinnomocylmalic acid in Thumbergia alata. Plant Physiology and Biochemistry. 2002, 40: 761-769.

[41] Tania F, Juan P F, Ana I C, et al. Effect of Salicylic acid treatment on tomato plant physiology and tolerance to potato virus X infection. European Journal of Plant Pathology. 2014, 138: $331-345$

[42] Don J, Wan G, Liang Z. Accumulation of salycilic acidinduced phenolic compounds and raised activities of secondary metabolic and antioxidative enzymes in Salvia miltiorrhiza cell culture. Journal of Biotechnology. 2010, 148: 99-104.

[43] Tchameni N S, Sameza L M, O'donovanb A, et al. Antagonism of Trichoderma asperellum against Phytophthora megakarya and its potential to promote cacao growth and induce biochemical defence. Mycology. 2017, 8: 84-92. 